\title{
Yield and cost of performing screening tests for constipation in children
}

\author{
Ashish Chogle MD MPH, Miguel Saps MD
}

\begin{abstract}
A Chogle, M Saps. Yield and cost of performing screening tests for constipation in children. Can J Gastroenterol 2013;27(12): e35-e38.
\end{abstract}

BACKGROUND: Chronic constipation is one of the most common reasons for pediatric outpatient visits. Clinical guidelines recommend that the work-up for chronic refractory constipation include thyroid function tests, celiac serology, and measurement of calcium and lead levels. Data to justify routine screening of constipated children using these laboratory tests are lacking.

OBJECTIVES: To study the prevalence of celiac disease, hypothyroidism, hypercalcemia and lead poisoning in children with chronic constipation; and to estimate the health care costs of applying the guideline recommendations.

METHOD: Charts of constipated children from 2007 to 2011 were reviewed for the present retrospective cohort study. Results and costs of thyroid function tests, celiac panel, total immunoglobulin ( Ig) A, and determination of lead and calcium levels were analyzed.

RESULTS: A total of 7472 children (mean age 7.9 years; 3908 female) were evaluated: 1731 patients were screened for celiac antibodies; 55 had elevated tissue transglutaminase IgA levels and 29 had biopsy-positive celiac disease. Only three celiac patients had constipation as the sole presenting symptom; 1703 patients were screened for total IgA levels; 55 had IgA deficiency and two had biopsy-positive celiac disease; 2332 had free T4 and/or thyroid-stimulating hormone levels; and 14 had hypothyroidism. Only two patients had constipation as the sole presenting symptom; 4651 patients had calcium levels measured, 10 of whom had high levels but normal repeat values. Three patients had normal lead levels. The mean cost per patient was USD $\$ 1,014$. Total screening cost for all patients was USD $\$ 4.7$ million.

CONCLUSION: Constipation alone did not increase the likelihood of celiac disease or hypothyroidism above the population prevalence. No benefit of screening for hypercalcemia was found. High health care costs were associated with the use of screening tests for organic constipation.

Key Words: Celiac disease; Children; Constipation; Costs; Hypercalcemia; Hypothyroidism; IgA deficiency; Lead poisoning; NASPGHAN he prevalence of chronic constipation in children in North

America varies between $2 \%$ and $27 \%$ (1-7). Chronic constipation is one of the most common complaints leading to ambulatory care visits in children (8). Approximately $3 \%$ of general pediatric outpatient visits and $25 \%$ of pediatric gastroenterology consultations are related to constipation (9). Children with constipation have more frequent outpatient consultations, emergency room visits and hospitalizations than children without constipation. Direct health care costs for children with constipation in the United States total $\$ 3.9$ billion per year $(10,11)$. Cumulative mean outpatient care costs for children with constipation are fourfold higher than in patients without constipation (11). Most outpatient consultations for constipation occur outside the neonatal period. Beyond the neonatal period, only a minority of children have an organic cause for constipation (12). In 2006,

\section{Le rendement et le coût des tests de dépistage de la constipation chez les enfants}

HISTORIQUE : La constipation chronique est l'une des principales raisons de consulter un pédiatre en consultations externes. Selon les directives cliniques, le bilan de la constipation réfractaire chronique doit inclure des tests de la fonction thyroïdienne, une sérologie cœeliaque et la mesure des taux de calcium et de plomb. On ne possède pas données pour justifier le dépistage systématique des enfants à l'aide de ces tests de laboratoire.

OBJECTIFS : Étudier la prévalence de maladie cœliaque, d'hypothyroïdie, d'hypercalcémie et d'empoisonnement au plomb chez les enfants atteints de constipation chronique et évaluer les coûts de santé liés à la mise en application des recommandations aux lignes directrices.

MÉTHODOLOGIE : Les chercheurs ont examiné les dossiers d'enfants constipés de 2007 à 2011 dans le cadre de la présente étude rétrospective de cohorte. Ils ont analysé les résultats et les coûts des tests de la fonction thyrö̈dienne, des tests sérologiques, du test d'immunoglobuline (Ig) de type A totale et la détermination des taux de plomb et de calcium.

RÉSULTATS : Au total, les chercheurs ont évalué 7472 enfants (3 908 filles; âge moyen de 7,9 ans). De ce nombre, 1731 ont subi un dépistage de la maladie coliaque, 55 présentaient un taux d'IgA élevé d'après la transglutaminase tissulaire, et 29 avaient une maladie coliaque positive à la biopsie. Seulement trois patients atteints d'une maladie coliaque avaient la constipation comme seul symptôme; 1703 patients ont subi le dépistage de l'IgA totale; 55 présentaient une carence en IgA et deux, une maladie coliaque positive à la biopsie, tandis que 2332 avaient une concentration de T4 libre ou un taux de thyrotropine et 14, une hypothyroïdie. Seulement deux patients avaient la constipation comme seul symptôme; on a mesuré le taux de calcium de 4651 patients, et dix d'entre eux avaient un taux de calcium élevé, mais des valeurs de reprise normales. Trois patients avaient un taux de plomb normal. Le coût moyen par patient s'élevait à 1014 \$US, et le coût de dépistage total de tous les patients, à 4,7 millions de dollars américains.

CONCLUSION : La constipation seule n'accroissait pas la probabilité de maladie coliaque ou d'hypothyroïdie au-delà de la prévalence en population. On n'a constaté aucun avantage au dépistage de l'hypercalcémie. Des coûts de santé élevés s'associent au recours à des tests de dépistage en cas de constipation organique.

Division of Pediatric Gastroenterology, Hepatology and Nutrition, Ann Eु Robert H Lurie Children's Hospital of Chicago, Feinberg School of Medicine,

Northwestern University, Chicago, Illinois, USA

Correspondence: Dr Ashish Chogle, Division of Pediatric Gastroenterology, Hepatology, $\mathcal{E}$ Nutrition, Ann $\mathcal{E}$ Robert H Lurie Children's Hospital of Chicago,

225 East Chicago Avenue, Chicago, Illinois 60611, USA. Telephone 312-227-4200, fax 312-227-9645, e-mail achogle@luriechildrens.org

Received for publication March 14, 2013. Accepted September 15, 2013 


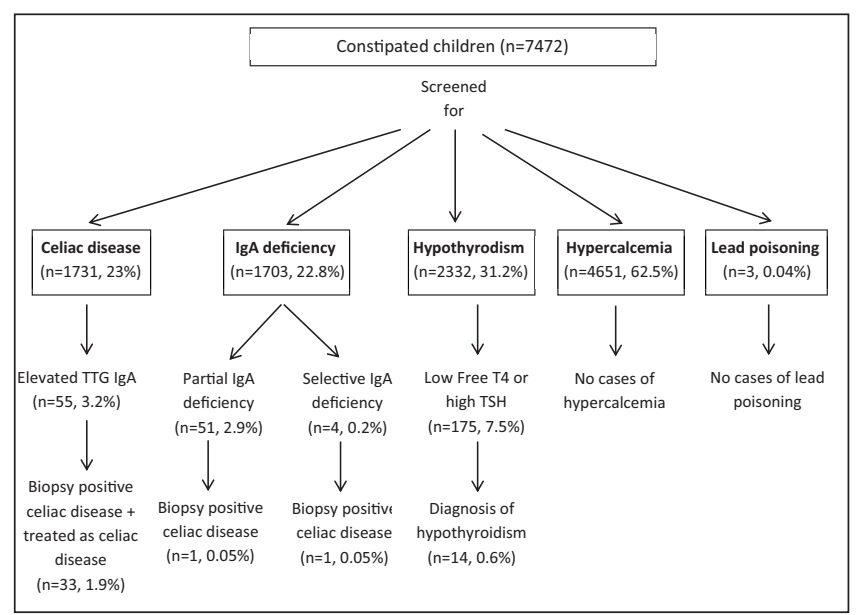

Figure 1) Results of screening of constipated children. Ig Immunoglobulin; TSH Thyroid stimulating hormone; TTG Tissue transglutaminase

diagnosing children with organic constipation. No study has assessed the overall costs involved in following all of NASPGHAN's testing recommendations. It is likely that an important portion of the direct medical costs for constipation-related medical visits result from testing. In times of limited resources and physicians who are increasingly sensitive to health care costs, the utility and total cost of these laboratory investigations needs to be assessed. We designed a study to assess the prevalence of celiac disease, hypothyroidism, hypercalcemia and lead poisoning in children with chronic constipation; and to estimate the health care costs that result from performing the screening tests for common organic causes of constipation in the evaluation of this group of children. We hypothesized that the routine performance of the recommended tests for the sole symptom of constipation would lead to high health care costs without increasing the rate of diagnosis of celiac disease, hypothyroidism, hypercalcemia and lead poisoning above the established community prevalence.

\section{METHODS}

The present retrospective, single-centre study was based on existing administrative and clinical data from Children's Memorial Hospital of Chicago (Illinois, USA). The electronic database of Children's Memorial Hospital (now Ann \& Robert H Lurie Children's Hospital of Chicago) expedited the retrieval of medical records and provided pertinent information for the study, which included the history of all patient encounters in the hospital and outpatient clinics, as well as laboratory and endoscopy results from all children cared for in the institution. Cases of constipation (International Classification of Diseases, Ninth Revision code 564) were identified by querying the electronic database of Children's Memorial Hospital for the period extending from January 2007 to December 2011. The medical records of all children who had a medical visit for constipation at Children's Memorial Hospital outpatient clinics were reviewed. Chart information regarding the presence of a medical outpatient visit for constipation was used to confirm the data from the electronic database search. Data regarding demographic characteristics and laboratory (celiac panel, TFTs, calcium and lead levels) and endoscopic evaluations of each patient were abstracted. Biopsy results of all patients with abnormal celiac serology who underwent endoscopy were examined. Each case with abnormal results was reviewed to determine whether the work-up suggested an organic cause of constipation. For the purpose of the present study, only patients who had the screening laboratory tests performed at the Children's Memorial Hospital or its satellite centres were included. Patients with preexisting diagnoses of celiac disease, thyroid dysfunction, calcium abnormalities, lead poisoning, inflammatory bowel disease or humoral immunodeficiency were excluded. All other patients with constipation, irrespective of their comorbidities, such as encopresis or abdominal pain, were included. At the Children's
Memorial Hospital, calcium levels are part of a 'metabolic panel' that includes sodium, potassium, blood urea nitrogen, creatinine, bicarbonate, chloride and glucose in its 'basic metabolic panel'. The 'comprehensive metabolic panel' includes all tests of the basic metabolic panel in addition to albumin, total protein and liver-related tests. Abnormal laboratory values were defined as follows: tissue transglutaminase (TTG) immunoglobulin (Ig) $\mathrm{A}>20 \mathrm{EIA} / \mathrm{U}$; selective IgA deficiency: $\operatorname{IgA}<0.067 \mathrm{~g} / \mathrm{L}$; partial IgA deficiency (for age $\geq 13$ years): $<0.7 \mathrm{~g} / \mathrm{L}$ and (for age $<13$ years) $<0.23 \mathrm{~g} / \mathrm{L}$; free $\mathrm{T} 4<10.3 \mathrm{pmol} / \mathrm{L}$ or $>19.3 \mathrm{pmol} / \mathrm{L}$; thyroid stimulating hormone $(\mathrm{TSH})<0.49 \mathrm{mIU} / \mathrm{L}$; lead level $>0.48 \mu \mathrm{mol} / \mathrm{L}$; calcium $<2.15 \mathrm{mmol} / \mathrm{L}$ or $>2.75 \mathrm{mmol} / \mathrm{L}$. Costs for the diagnostic tests and consultations were estimated using the amounts charged by the hospital to the payer in 2011. Costs for endoscopies included operating and recovery room charges, medications and supplies, anesthesia, pathology and physician procedure fees. The present study was approved by the institutional review board of Children's Memorial Hospital of Chicago.

\section{RESULTS}

A total of 7472 patients were seen for the primary diagnosis of constipation. Patients had a mean age of 7.9 years (range four months to 21 years) and 3908 (52.3\%) were female (Figure 1). Children were of various ethnicities and races: 40\% Caucasian, 36\% Hispanic, 15\% African American, 3\% Asian and 1\% Native American.

\section{Celiac disease}

Twenty-three per cent $(n=1731)$ of patients were screened for celiac disease (mean age 1.5 to 8.8 years; $53.7 \%$ female). Of the patients screened, 3.2\% ( $n=55)$ had elevated TTG IgA levels, 2.1\% $(n=37)$ had undergone an upper endoscopy and $1.7 \%(n=29)$ had biopsy-positive celiac disease. Three patients with TTG IgA levels >100 EIA/U did not undergo biopsies but were treated with gluten-free diet. One patient with TTG IgA $<100 \mathrm{EIA} / \mathrm{U}$ was treated with gluten-free diet (repeat TTG IgA levels were not available for review). If these four patients without biopsies were included in the analysis, the prevalence of celiac disease was $1.9 \%$. Only $0.2 \%(n=3)$ of patients diagnosed with celiac disease had constipation as their sole presenting symptom. Other patients experienced abdominal pain (31\%), vomiting (17\%), abdominal distension (10\%), growth/weight abnormalities (10\%), intermittent diarrhea $(10 \%)$, rash $(7 \%)$ or a combination of the above symptoms in addition to constipation.

\section{Celiac disease and selective IgA deficiency}

IgA serology was performed in $22.8 \%(n=1703)$ of patients. Of the patients screened, $2.9 \%(\mathrm{n}=51)$ had partial IgA deficiency, $0.2 \%$ $(n=4)$ had selective IgA deficiency, $1.4 \%(n=24)$ underwent upper endoscopies and $0.1 \%(n=2)$ had biopsy-positive celiac disease. Of the patients diagnosed with celiac disease, one had selective IgA deficiency and the other had partial IgA deficiency.

\section{Thyroid disorders}

$31.2 \%(n=2332)$ of patients underwent a TFT. Of the patients screened, $7.5 \%(n=175)$ had low free T4 and/or high TSH levels. Of these 175 patients, 128 had normal repeat TFTs; $0.8 \%(n=20)$ patients with abnormal TFTs on repeat testing were referred to the endocrinology department for an outpatient consult: $0.6 \% \quad(n=14)$ were diagnosed with hypothyroidism on repeat testing of levels and were treated with thyroid hormone replacement. Twenty-seven patients did not undergo any testing nor were they sent for endocrine consultation. These patients were not given a diagnosis of hypothyroidism as per the chart review.

Twelve $(0.5 \%)$ of the patients who were tested for hypothyroidism had slow growth, abdominal pain, vomiting or a combination of these symptoms in addition to constipation. Only $0.08 \%(n=2)$ of patients had constipation as the sole presenting symptom. No patients were diagnosed with hyperthyroidism, $4.9 \%(n=115)$ of patients had high free T4 levels and/or low TSH levels with normal repeat values. 


\section{Calcium abnormalities}

Sixty-two per cent $(n=4651)$ of patients had calcium levels measured. No patients were diagnosed with hypercalcemia; 0.2\% $(n=10)$ had high calcium levels $(>2.75 \mathrm{mmol} / \mathrm{L})$ with normal repeat values.

\section{Lead poisoning}

Only three patients underwent testing for lead levels and all were normal.

\section{Financial burden of testing}

The total billed charges for all investigations performed was USD $\$ 4,719,575$ (Table 1). The mean $( \pm$ SD) charge to evaluate one patient with constipation was USD $\$ 1,014 \pm 1,412$. The mean charges incurred in discovering a newly diagnosed patient with: celiac disease $\$ 67,397$, hypothyroidism USD $\$ 82,016$ and IgA deficiency with celiac disease USD $\$ 127,725$. The costs associated with the 20 patients with abnormal TFTs who were referred for endocrinology consultations added an additional USD $\$ 16,000$ in consultation charges.

\section{DISCUSSION}

Our study showed that few children with constipation who undergo NASGPHAN guideline-recommended laboratory testing are diagnosed with a new organic disease. Only $1.7 \%$ of 1731 screened, constipated children were diagnosed with celiac disease and only $0.2 \%$ $(n=3)$ who had constipation as the sole symptom were found to have celiac disease. The yield of testing for other diseases was even more underwhelming. Only $0.6 \%$ of constipated children and $0.08 \%(n=2)$ of children who had constipation as the sole presenting symptom were diagnosed with hypothyroidism and none of our patients were diagnosed with hypercalcemia. In none of these diseases did the prevalence of children found to have an organic disease exceed the known community prevalence. The prevalence of celiac disease in children ranges between $1.7 \%$ and $2.8 \%$ in North America $(14,15)$. The prevalence of clinical hypothyroidism in children in North America ranges from $0.3 \%$ to $0.6 \%$ (16). Thus, the likelihood of finding a patient with celiac disease and hypothyroidism by screening constipated children, is no greater than the likelihood of finding a case of both of these conditions by random screening of the population. This likelihood decreases even further if we only consider the 'healthy' children who present with constipation as their sole symptom. Selective IgA deficiency or partial deficiency has been shown to be present in $2 \%$ of celiac disease patients (17). In clinical practice, the screening of patients for celiac disease frequently includes measuring IgA levels to identify patients with $\operatorname{IgA}$ deficiency and, consequently, false-negative celiac IgA antibodies. Although IgA levels are not a component of the NASPGHAN recommendations, we decided to assess their utility in diagnosing additional cases of celiac disease. Only $0.1 \%$ of patients who were screened for IgA deficiency were found to have celiac disease.

A question that can be asked is whether our study contradicts the existing literature that reports a higher risk of constipation in patients with celiac disease, hypothyroidism, hypercalcemia or lead intoxication. The results of our study do not defy the published literature. A primary care-based study involving 976 subjects found celiac disease in 22 subjects. Only four of the 22 celiac disease patients $(0.4 \%$ of the total sample) underwent celiac screening for presenting symptoms of constipation (18). Patients with celiac disease experience an increased frequency of constipation. However, testing all patients with a common condition, such as constipation, may not be cost effective nor increase the odds of finding an infrequent condition such as celiac disease. This concept is frequently applied in other areas of medicine. The fact that there is an increased risk of rare cancers (ie, small bowel) in patients who receive immunomodulators is not associated with a recommendation for routine small bowel cancer screening in all patients who receive immunomodulators. Applying the same principle to constipation could lead to a change in recommendations.

Previous studies have documented high health care costs related to constipation. The mean outpatient cost of managing a patient with

\section{TABLE 1}

Cost of evaluating constipation in children

\begin{tabular}{lccr}
\hline & Tests & \multicolumn{2}{c}{ Charges, \$USD } \\
\cline { 3 - 4 } Test & perfomed, $\mathbf{n}$ & Billed & \multicolumn{1}{c}{ Total } \\
\hline Celiac antibody panel & 1731 & 744 & $1,287,864$ \\
Antiendomysial antibody & 73 & 311 & 22,703 \\
Immunoglobulin A level & 1703 & 150 & 255,450 \\
Basic metabolic panel & 4086 & 245 & $1,001,070$ \\
Comprehensive & 871 & 397 & 345,787 \\
$\quad$ metabolic panel & & & \\
Thyroid function test & 2627 & 431 & $1,132,237$ \\
Upper endoscopy & 61 & 10,788 & 658,068 \\
Lead level & 3 & 132 & 396 \\
Endocrine consultation & 20 & 800 & 16,000 \\
& & & $4,719,575$ \\
\hline
\end{tabular}

constipation in Olmsted county (Minnesota, USA) was estimated to be USD $\$ 13,927$ (19). Another study found that the overall national health services utilization per child with constipation is $\operatorname{USD} \$ 3,430$ per year (10). Although the expenses and methods of the different studies vary, all studies indicate that the costs of managing children with constipation are enormous. Our study provides insight into some of the issues that may be responsible for the high health care expenses. We found that a significant portion of this cost can be attributed to the laboratory evaluations conducted to screen for organic constipation. The health care expenditure for diagnosing constipated patients with celiac disease or hypothyroidism was found to be staggering. The cost of diagnosing one patient with hypothyroidism or celiac disease is even higher if we only consider children who have constipation as their sole presenting symptom. There was no value in requesting calcium level determination. The fact that calcium determination is usually sent as part of a battery of tests that increase the cost of screening questions this indication even further.

The low diagnostic yield of testing found should prompt the medical community to conduct prospective studies specifically designed to assess common practices and analyze the costs and yield of each medical action. Total costs incurred for evaluation of children in our study were likely above and beyond the charges documented because indirect costs to the family, such as arranging child care for other children, missed work for additional appointments and transportation costs to the laboratory, were not included in the above calculations. Other costs not included in our study are those of testing performed at outside facilities and repeat laboratory testing, which are sometimes sent by physicians to confirm the negative results of the initial work-up for organic constipation. A study by Liem et al (10) found that 1.7 million children in the Unites States experience constipation. More than $30 \%$ of children with constipation are considered to have refractory constipation (20-22). Based on the most conservative estimates of these data, more than 0.5 million American children could carry the diagnosis of refractory constipation. If all of these children had the same average diagnostic costs as the children in our hospital (USD\$1,014), it would amount to >USD $\$ 0.5$ billion dollars in testing charges. Moreover, if all children with refractory constipation would receive all testing recommended by NASPGHAN, diagnostic charges would amount to USD\$2,013 per patient.

Although the purpose of the present study was limited to reporting common practices, testing costs and yield of testing in a tertiary care centre (we do not believe that changes in practice recommendations should be based on a single study), our study calls to attention our way of practice. In the current health care environment, which stresses eliminating wasteful spending, common practices may need to be reviewed and recommendations based on low levels of evidence, such as in the case of laboratory testing for constipation, reconsidered. Given the high cost of finding one patient with organic constipation, it could be suggested that children be evaluated on a case-by-case basis for the need of 
screening. Considering the high expense of finding a patient with selective IgA deficiency, physicians should consider limiting the screening for IgA deficiency to patients with other symptoms of celiac disease or the presence of family history of celiac disease, or autoimmunity or elevated IgG antibody levels on the celiac panel. Testing in children with constipation as the sole symptom should be carefully considered because testing is unlikely to unveil an organic disease.

The present retrospective analysis was limited by the fact that we could not accurately assess the duration of constipation at the time of the laboratory work-up. We did attempt to conduct this analysis, but were not successful due to inadequate documentation in some of the charts. It is common practice in our hospital that the patients seen at the pediatric gastroenterology clinics for constipation are first treated by general pediatricians for at least a few months. Most of these patients are started on laxatives by their pediatricians. Pediatric gastroenterologists generally send screening tests for constipation only after failing laxative therapy. Therefore, we conducted the analysis based on the assumption that most of our patients who underwent laboratory investigations had chronic refractory constipation. Services and utilization patterns in our institution may be different than others in the United States and, therefore, may not be generalizable. Although it could be argued that the population served at Children's Memorial Hospital may differ from other sites, the ethnic and racial composition of our sample is almost identical to the population characteristics of a large study of the Medical Expenditure Panel Survey,

\section{REFERENCES}

1. Chitkara DK, Talley NJ, Locke GR III, et al. Medical presentation of constipation from childhood to early adulthood: A populationbased cohort study. Clin Gastroenterol Hepatol 2007;5:1059-64.

2. Higgins PD, Johanson JF. Epidemiology of constipation in North America: A systematic review. Am J Gastroenterol 2004;99:750-9.

3. Pare P, Ferrazzi S, Thompson WG, Irvine EJ, Rance L. An epidemiological survey of constipation in Canada: Definitions, rates, demographics, and predictors of health care seeking. Am J Gastroenterol 2001;96:3130-7.

4. Sandler RS, Jordan MC, Shelton BJ. Demographic and dietary determinants of constipation in the US population. Am J Public Health 1990;80:185-9.

5. Stewart WF, Liberman JN, Sandler RS, et al. Epidemiology of constipation (EPOC) study in the United States: Relation of clinical subtypes to sociodemographic features. Am J Gastroenterol 1999:94:3530-40.

6. Talley NJ, Weaver AL, Zinsmeister AR, Melton LJ III. Functional constipation and outlet delay: A population-based study. Gastroenterology 1993;105:781-90.

7. van den Berg MM, Benninga MA, Di Lorenzo C. Epidemiology of childhood constipation: A systematic review. Am J Gastroenterol 2006;101:2401-9.

8. Sonnenberg A, Koch TR. Physician visits in the United States for constipation: 1958 to 1986. Dig Dis Sci 1989;34:606-11.

9. Molnar D, Taitz LS, Urwin OM, Wales JK. Anorectal manometry results in defecation disorders. Arch Dis Child 1983;58:257-61.

10. Liem O, Harman J, Benninga M, Kelleher K, Mousa H, Di Lorenzo C. Health utilization and cost impact of childhood constipation in the United States. J Pediatr 2009;154:258-62.

11. Choung RS, Branda ME, Chitkara D, et al. Longitudinal direct medical costs associated with constipation in women. Aliment Pharmacol Ther 2011;33:251-60.

12. Loening-Baucke V. Chronic constipation in children. Gastroenterology 1993;105:1557-64. which represents 158 million children nationally (10). We used billed charges in our study to facilitate calculation because the insurance reimbursements vary in different states and according to the contracts with individual hospital systems. On average, the reimbursements vary between $20 \%$ and $60 \%$ of the billed charges at our institution.

\section{CONCLUSION}

Constipation alone did not increase the likelihood of finding celiac disease or hypothyroidism above the population prevalence. We found no benefit of screening for hypercalcemia. High health care costs were associated with the use of screening tests for organic constipation. The results of our study should be taken in consideration by pediatricians and pediatric gastroenterologists at the time of evaluating children with constipation. The findings of our singlecentre, tertiary care-based study warrant conducting prospective multicentre studies to confirm our findings and assess the cost effectiveness of conducting serological testing in children with constipation. The results of the current and future studies may be valuable when NASPGHAN guidelines for constipation are revised.

DISCLOSURES: The authors have no financial disclosures or conflicts of interest to declare. There were no funding sources for this publication.

13. Evaluation and treatment of constipation in infants and children: recommendations of the North American Society for Pediatric Gastroenterology, Hepatology and Nutrition. J Pediatr Gastroenterol Nutr 2006;43:e1-e13.

14. Fasano A, Berti I, Gerarduzzi T, et al. Prevalence of celiac disease in at-risk and not-at-risk groups in the United States: A large multicenter study. Arch Intern Med 2003;163:286-92.

15. Hill I, Fasano A, Schwartz R, Counts D, Glock M, Horvath K. The prevalence of celiac disease in at-risk groups of children in the United States. J Pediatr 2000;136:86-90.

16. Hollowell JG, Staehling NW, Flanders WD, et al. Serum TSH, $\mathrm{T}(4)$, and thyroid antibodies in the United States population (1988 to 1994): National Health and Nutrition Examination Survey (NHANES III). J Clinic Endocrinol Metabol 2002;87:489-99.

17. Chow MA, Lebwohl B, Reilly NR, Green PH. Immunoglobulin A deficiency in celiac disease. J Clin Gastroenterol 2012;46:850-4.

18. Catassi C, Kryszak D, Louis-Jacques O, et al. Detection of celiac disease in primary care: A multicenter case-finding study in North America. Am J Gastroenterol 2007;102:1454-60.

19. Choung RS, Shah ND, Chitkara D, et al. Direct medical costs of constipation from childhood to early adulthood: A populationbased birth cohort study. J Pediatr Gastroenterol Nutr 2011;52:47-54.

20. Youssef NN, Di Lorenzo C. Treatment options for refractory childhood constipation. Curr Treat Option Gastroenterol 2002;5:377-87.

21. Michaud L, Lamblin MD, Mairesse S, Turck D, Gottrand F. Outcome of functional constipation in childhood: A 10-year follow-up study. Clin Pediatr 2009;48:26-31.

22. van Ginkel R, Reitsma JB, Buller HA, van Wijk MP, Taminiau JA, Benninga MA. Childhood constipation: Longitudinal follow-up beyond puberty. Gastroenterology 2003;125:357-63. 


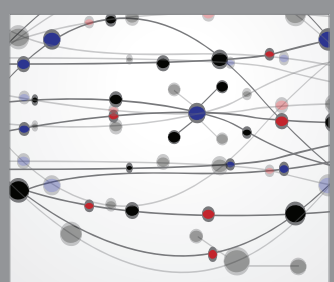

The Scientific World Journal
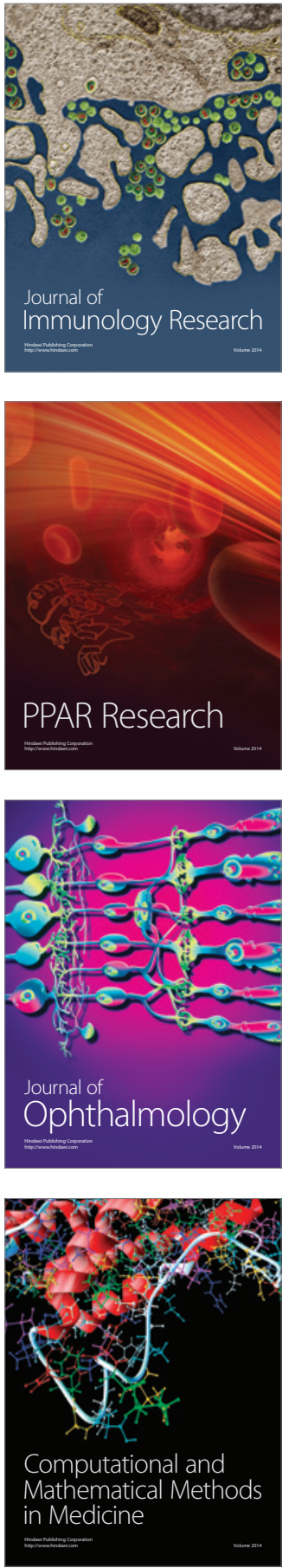

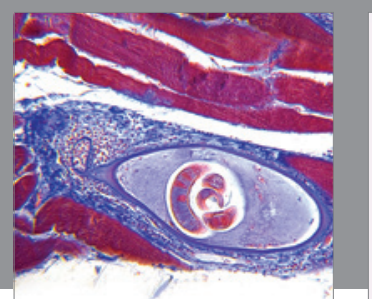

Gastroenterology Research and Practice

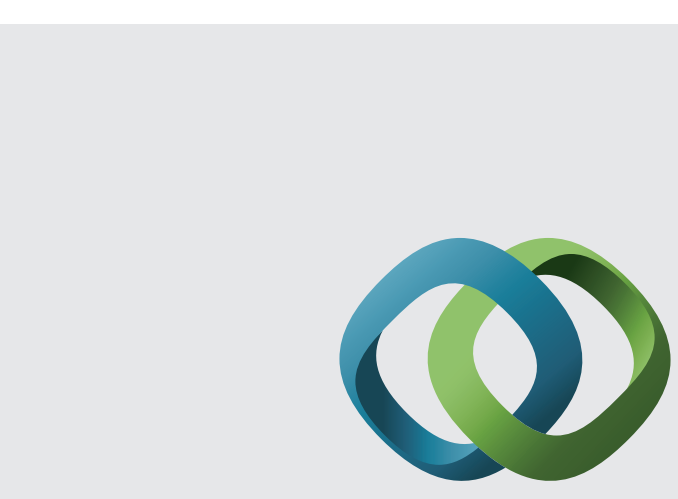

\section{Hindawi}

Submit your manuscripts at

http://www.hindawi.com
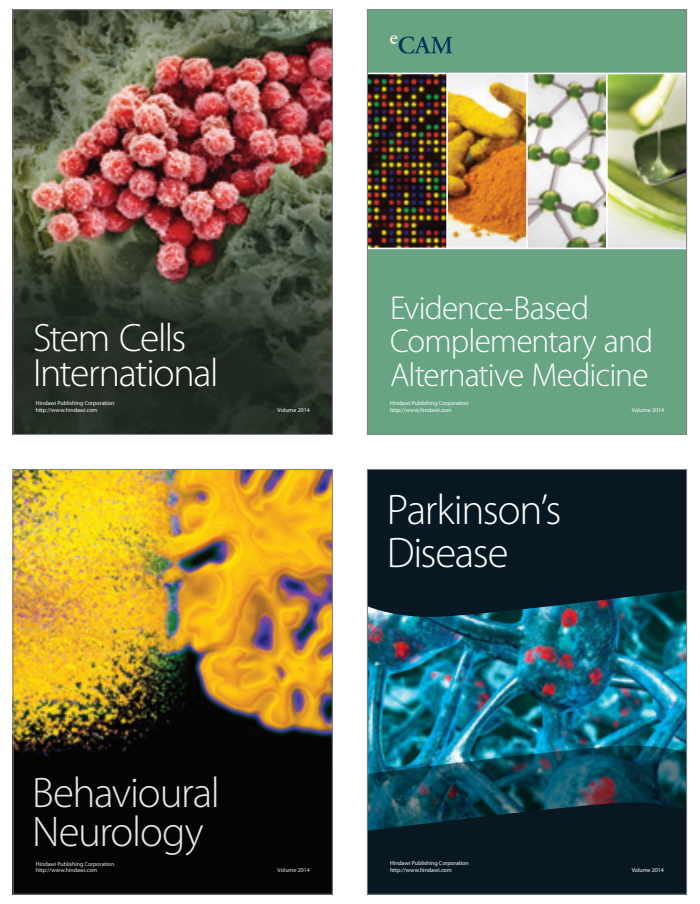
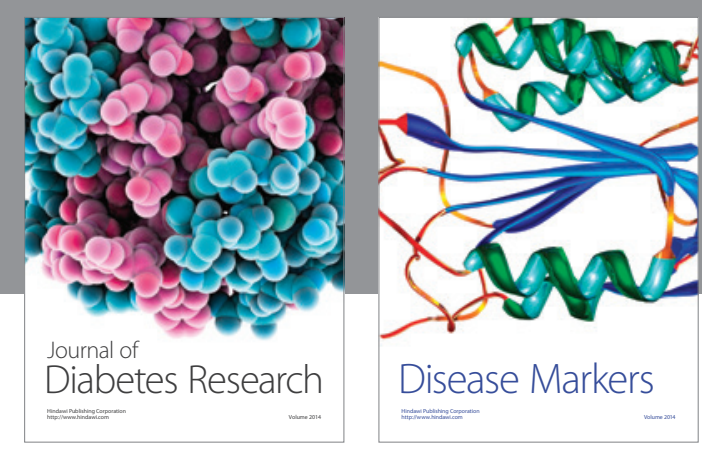

Disease Markers
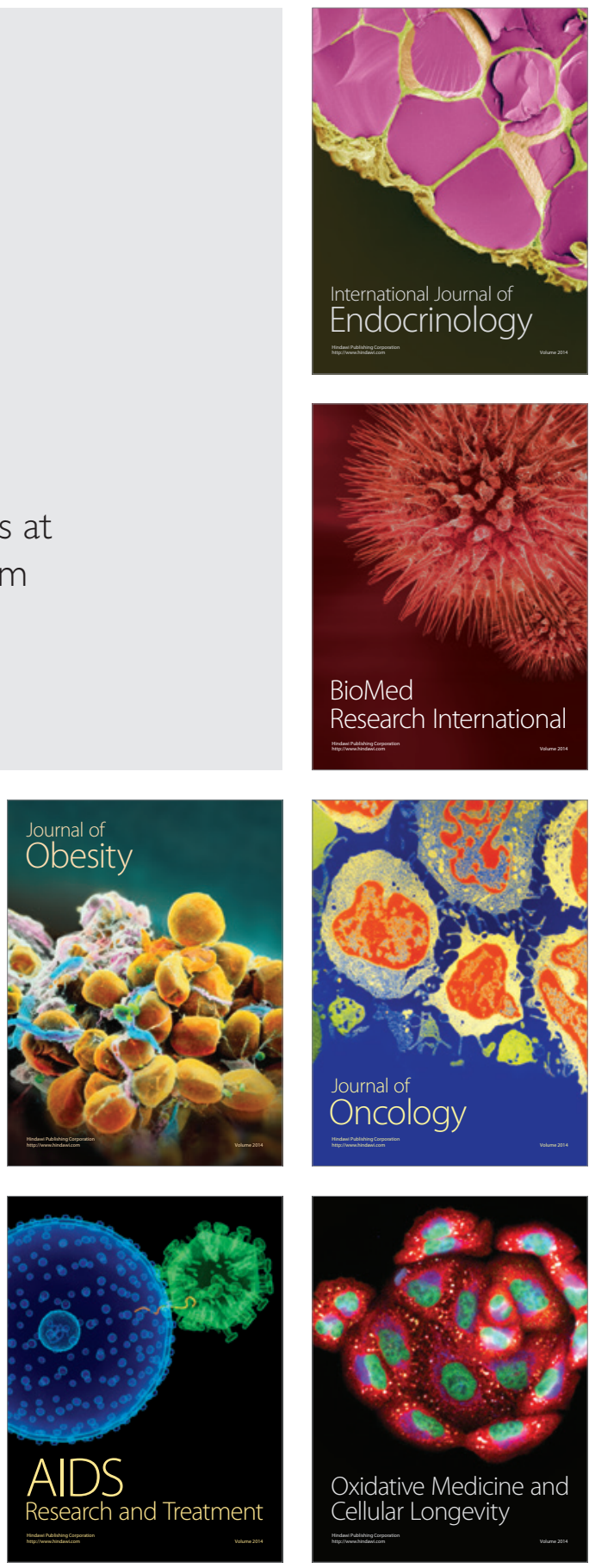